\section{Deaths from asthma in children on aerosol corticosteroids}

Between 1961 and 1966 the number of deaths from bronchial asthma rose alarmingly, particularly in children. This alerted the medical profession for the first time to the potential dangers of drug treatment in that disease. ${ }^{1}$ The simplistic view that this "epidemic" of asthma deaths was wholly due to the overuse of bronchodilator aerosols, particularly those containing isoprenaline, is no longer widely held, ${ }^{2}$ but the deaths and their investigation did have the valuable effect of directing attention to the possible hazards of every new treatment for asthma.

Aerosol corticosteroids were introduced in 1968 and proved effective in many patients who would otherwise have been exposed to the considerable risks of systemic treatment. Candidiasis affecting the oropharynx and occasionally the larynx is a fairly common side effect, ${ }^{3}$ but there is no evidence that it ever extends to the bronchi or lungs. Anxiety that the prolonged administration of a corticosteroid aerosol could cause epithelial atrophy and damage collagen and elastic tissue in the respiratory tract has not yet been justified. A recent study of biopsy specimens ${ }^{4}$ found no such changes in the bronchial epithelium or submucosa. So far this form of treatment seems unlikely to prove a specific cause of mortality or serious morbidity in patients with bronchial asthma. Corticosteroid aerosols are, however, often used to replace systemic corticosteroids partially or completely, so that the suggestion made by Mellis and Phelan ${ }^{5}$ that weaning from long-term systemic treatment in these circumstances may increase the risk of sudden death in children with severe chronic asthma clearly warrants critical attention.

Mellis and Phelan reported the deaths of five such children over a 12-month period. Two of the children had not been treated with a corticosteroid aerosol, and the necropsy findings were typical of bronchial asthma, with extensive mucus plugging of the smaller bronchi. In contrast, the other three had been treated with a beclomethasone dipropionate aerosol while systemic corticosteroid treatment was being withdrawn. All had acute inflammatory changes in the lungs at necropsy, with no mucus plugging. Those observations imply that an infective process (presumably viral, since there was no convincing pathological evidence of bacterial infection) was responsible for the death of these three children and that the corticosteroid aerosol may have contributed in some way.

Children with severe chronic asthma who have been treated with systemic corticosteroids for long periods are always in a precarious state. Even a slight increase in hypoxia, such as could be produced by viral infection, can result in sudden death; and this is all the more likely if the pituitary-adrenal response to stress has been impaired by the prolonged administration of corticosteroids. The risk is even greater if infection occurs shortly after this treatment is withdrawn or even when the maintenance dose has been substantially reduced. Perhaps, then, the main reason why these children die is that they are being given an inadequate dose of systemic corticosteroid. If that is so, Mellis and Phelan's only real justification for their suggestion that aerosol corticosteroid treatment may have contributed to the deaths they reported is that the dose of systemic corticosteroid might have been reduced less rapidly, if at all, in three of their five cases had aerosol therapy not been available. Some doctors stop systemic treatment abruptly after aerosol therapy is introduced, ${ }^{6}$ but recovery of a normal pituitary-adrenal response to stress may take as long as a year, ${ }^{7}$ and throughout that period the life of a child with severe chronic asthma is constantly at risk.

Rapid withdrawal of systemic treatment is therefore both unwise and unnecessary, and if prednisolone is the drug being used the daily dose should be reduced at a rate not exceeding $1 \mathrm{mg}$ per month. Such a policy will give the pituitary-adrenal axis more time to recover; but it cannot protect every child from the consequences of an acute respiratory infection or a severe attack of asthma. In that event the urgent need is treatment with massive doses of systemic corticosteroids and immediate admission to a respiratory intensive therapy unit. Nevertheless, in some cases, unfortunately, the child may die suddenly before these measures can be implemented. Caution in withdrawing systemic corticosteroids and a more realistic appreciation of the limitations of aerosol corticosteroids might prevent some at least of these fatalities.

Speizer, F E, Doll, R, and Heaf, P, British Medical fournal, 1968, 1, 335. British Medical fournal, 1972, 1, 459.

Willey, R F, et al, British Fournal of Diseases of the Chest, 1976, 70, 32.

Anderson, E, et al, British Fournal of Diseases of the Chest, 1977, 71, 35.

Mellis, C M, and Phelan, P D, Thorax, 1977, 32, 29.

${ }^{6}$ Brown, H M, Storey, G, and George, W H S, British Medical fournal, $1972,1,585$.

'Malone, D N S, et al, British Medical fournal, 1972, 3, 202.

\section{The Mahler revolution}

Under the direction of Dr Halfdan Mahler the activities of the World Health Organisation have undergone a quiet revolution in the past few years. In keeping with other organisations of the United Nations, WHO channels its activities through the governments of the countries in which it operates. The former emphasis on universities and their medical schools has now swung towards primary health care and basic health servicesa change spelt out in the resolutions of the 1975 World Health Assembly, which stated that all other echelons of the health services should support the needs of their peripheral activities. This is a great contrast from recent policies in most developing countries, where the financial commitments-and the interest of politicians-have been to teaching hospitals and other services, mainly in the cities.

The change is not easy, as our own Ministry of Overseas Development has discovered. While priority is now to be given to aid to the poorest countries-and the least privileged people in those countries-it may prove more difficult to use money effectively in this way than in building "disease palaces." The new emphasis on basic health services means, for example, that money needs to be spent on an adequate supply of vaccines and low cost drugs to prevent or treat common conditions, making less money available for rarer diseases requiring expensive facilities. Governments may pay lip service to such a programme, but change will be difficult to achieve; for these new policies will soon lead to the cutting back of services to the politically vocal city-dweller, at times supported by those senior medical men to whom the politician turns for his own personal health care.

In any health service the cost of employing health workers and their supporters is the largest single expenditure. But unfortunately, when we examine how many doctors in the underdeveloped countries spend their time-preferring to live in towns rather than in the rural areas-we find that much 
of what they do could be done equally well (and frequently better) by medical assistants and others with limited and relatively cheap training. Furthermore, auxiliary health workers do not expect or receive the high pay and living standards of the doctor.

The poor socioeconomic conditions of rural and slum areas in most developing countries lead to a very high mortality from the interaction of malnutrition and infection. Even in the better hospitals the management of children with malnutrition may be poor and many die $^{1}$ : clearly a different approach is needed. One solution is nutrition rehabilitation, but it has taken until 1977 for the first book on this subject to be published. ${ }^{2}$ Meanwhile whooping cough, tuberculosis, tetanus, poliomyelitis, and diphtheria still exact an enormous toll in morbidity and mortality among malnourished children in developing countries. The spectacular success in virtually eliminating smallpox has proved the value of immunisation programmes, though in no other disease is early eradication likely. Through its extended immunisation programme WHO is tackling the logistic and geographical problems, ${ }^{3}$ including keeping vaccines refrigerated all the way along their distribution networks-the "cold chain."

Another direct and simple step that can be taken through the new policy of community participation is the use of oral rehydration. ${ }^{45}$ This can be carried out in villages without hospitals and has proved immensely successful: once the programme has been learnt, the hospitals rarely see severely dehydrated children.

This switch in policy to health by the people, with greater emphasis on self-reliance, will produce health services which they themselves can understand, afford, and direct. It offers a new challenge to the World Health Organisation, to governments, and to ministries of health in both the industrial and developing countries. Unfortunately, many will see such a policy as a threat to themselves and the power they presently wield; for the changes in emphasis in developing health services call for a fundamental change in training health workers. Training based on existing European or American patterns is even less relevant in the developing than in the industrial countries. New curricula are being developed in the form of "packages" or "microplans" for auxiliaries and village workers, ${ }^{6}$ in which the teaching is relevant to the needs and resources that are available. Despite some resistance from some doctors this is a concept to which the World Health Organisation is now heavily committed.

\footnotetext{
${ }^{1}$ Cook, R J, fournal of Tropical Pediatrics and Environmental Child Health, $1971,17,15$.

2 Koppert, J, Nutrition Rehabilitation. London, Trimed, 1977.

3 Lloyd, J S, WHO Chronicle, 1977, 31, 13.

4 Lancet, 1975, 1, 79.

5 Pierce, N F, and Hirschhorn, N, WHO Chronicle, 1977, 31, 87.

6 Newell, K W, King, M H, and Suliantiaroso, S J, WHO Chronicle, 1975, 29, 12.
}

\section{Postponing premature labour}

Prematurity is the most important avoidable cause of perinatal mortality and morbidity in Britain today. Premature delivery may occur because of a complication of pregnancy, but often it results from uncomplicated spontaneous premature labour, which accounts for $30 \%$ of low birthweight babies. ${ }^{1}$ Prevention is difficult, because identification of patients at risk-the young, the unmarried, and those who smoke-selects only relatively few of the women who will go into premature labour. ${ }^{2}$ The alternative approach is to find an effective treatment, but opinion is divided over the best method. ${ }^{3-5}$ Conservative treatment (bed rest and sedation) will be followed by cessation of contractions in between $40^{\circ}{ }_{0}$ and $70^{\circ}{ }_{0}$ of cases, ${ }^{6-9}$ and, since this has no side effects, any more active treatment needs to prove itself substantially better.

Intravenous ethanol interferes with the release of oxytocin from the posterior pituitary ${ }^{10}$ and in one controlled trial postponed labour more effectively than bed rest alone, ${ }^{7}$ though subsequent studies $^{6 *}$ have not confirmed this. Side effects include nausea and vomiting, with the danger of aspiration pneumonia, ${ }^{8}$ and overdosage may cause acidosis. ${ }^{11}$

More widely used are the $\beta$-sympathomimetic agents: isoxsuprine, for example, was found more effective than either bed rest or alcohol in a controlled trial, ${ }^{6}$ but tachycardia and hypotension are frequent side effects and limit its usefulness. The more recent drugs such as ritodrine are said to be more specific for the $\beta_{2}$ receptors (those in smooth muscle of organs such as bronchus and uterus ${ }^{12}$ ) and to have less effect on the cardiac $\beta_{1}$ receptors. The effectiveness of ritodrine ${ }^{9}$ and of the related drugs terbutaline ${ }^{13}$ and nylidrin ${ }^{6}$ has been confirmed by controlled trials: in each study $80^{\circ}{ }_{0}$, or more of treated patients had labour delayed at least until the end of treatment. Trials of salbutamol have lacked controls, ${ }^{14}$ and there has been none comparing the different $\beta_{2}$-mimetics with one another. At first all are given intravenously and then orally, and the best results have come from tailoring the dosage to the individual patient rather than following a fixed schedule.

Side effects are more than usually important in pregnant patients. Ritodrine produces maternal tachycardia ${ }^{9}$ but is said not to cause hypotension. ${ }^{15}$ In sheep ritodrine produces a fall in uterine blood flow, ${ }^{16}$ but in women with hypertension or intrauterine growth retardation uterine blood flow increases, an effect claimed to promote growth of the small-for-dates fetus. ${ }^{17}$ Enhancement of growth is unlikely to be due to any diabetic-like state it induces, for carbohydrate tolerance is normal in treated mothers and their newborn babies. ${ }^{18}$ Occasional other side effects such as bowel distension have been recorded with $\beta$-mimetics. ${ }^{19}$

When the doctor should try to postpone premature labour must remain a question of clinical judgment, though any condition (such as accidental haemorrhage) threatening the fetus contraindicates such action. Treatment should be started as soon as possible after contractions begin, even if such a policy will lead to unnecessary treatment in cases of false labour. Once the membranes have ruptured treatment is rarely effective ${ }^{9}$; furthermore, it may be contraindicated because of the risk of infection. ${ }^{+}$In such cases it may be worthwhile to try to delay labour for 24 hours to give the fetal lungs a chance to mature, especially if steroids have been given to stimulate the production of surfactant. ${ }^{20}$

For the time being treatment is still directed at the uterine contractions rather than at factors initiating labour, which remain poorly understood. Endocrine changes do occur in patients going into premature labour, ${ }^{21}$ and more research into its pathophysiology should lead to further improvements in treatment.

1 Fedrick, J, and Anderson, A B M, British fournal of Obstetrics and Gynaecology, 1976, 83, 342.

2 Fedrick, J, British fournal of Obstetrics and Gynaecology, 1976, 83, 351.

3 Koh, K S, Canadian Medical Association Fournal, 1976, 114, 700

- Zuspan, F P, Fournal of Reproductive Medicine, 1972, 9, 93.

${ }^{5}$ Lancet, 1974, 2, 875.

6 Castren, O, Gummerus, M, and Saarikoski, S, Acta Obstetricia et Gynecologica Scandinavica, 1975, 54, 95.

7 Zlatnik, F J, and Fuchs, F, American fournal of Obstetrics and Gynecology, $1972,112,610$ 